\title{
SPLENIC AGENESIS AND MULTILOBULATE SPLEEN
}

\author{
BY \\ C. S. MUIR \\ From the Department of Pathology, University of Malaya, Singapore
}

(RECEIVED FOR PUBLICATION MARCH 20, 1959)

Agenesis of the spleen has for many years been held to be extremely rare, and of interest only to the morbid anatomist. Since it was shown (Gasser and Willi, 1952; Willi and Gasser, 1955) that diagnosis in vivo is possible, interest in the lesion, and in the cardiac anomalies usually found with it, has increased.

This paper records the incidence of splenic agenesis, and of the closely allied condition of multilobulate spleen, in the past 22,500 autopsies performed at the General Hospital, Singapore.

Of these, 520 died with some form of congenital heart disease. In this latter group seven cases of splenic agenesis and one of multilobulate spleen were found. Splenic agenesis without cardiac malformation occurred in one instance: a case of multilobulate spleen associated with hydranencephaly and a normal heart has been reported elsewhere (Muir, 1959) and is not included in this series.

\section{Splenic Agenesis}

Case 1. Chinese male, aged 6 weeks. Complaint: cyanosis and diarrhoea. P.M. 731/51. There was dextrocardia, the aortic arch being right-sided. From a biloculate heart a large common trunk arose, the lungs being supplied by a patent ductus arteriosus. There was a congenitally short oesophagus, most of the stomach being intrathoracic. The duodenum and pancreas were situated normally; the liver was central, the gall bladder being found on the right lobe. There was a central mesentery.

Case 2. Chinese male, aged 1 year. Complaint: cyanosis and gangrene of left leg. P.M. 769/52. There was dextrocardia. Both interventricular and interauricular septa were rudimentary. A four-cusped atrioventricular valve was inserted into the apex of the common ventricle. The aortic arch and aorta were leftsided. There was adherent greyish thrombus at the bifurcation of the left common iliac vessel and in the right-sided superior vena cava. Both lungs showed three lobes. The liver was symmetrical. The stomach was left-sided, the mesentery central, the caecum in the left flank, and the descending colon in the right.

Case 3. Chinese female, aged 1 month. Complaint: dyspnoea, cyanosis and refusal of feeds. P.M. 2135/53.
The venae cavae opened into the left atrium, the pulmonary veins draining into the superior vena cava as it entered the atrium. There was a large atrio-septal defect, allowing blood to enter the right atrium. The pulmonary artery arose normally from a thick-walled dilated right ventricle. Each lung showed three lobes. A small diaphragmatic hernia contained the fundus of the stomach. Stomach, pancreas and duodenum were transposed.

Case 4. Chinese male, aged 1 month. Complaint: dyspnoea and cyanosis. P.M. 1578/54. There was a single hypertrophied dilated ventricle from which a right-sided aorta arose. The pulmonary artery arose from the same chamber. The ductus arteriosus was widely patent; there was a large atrio-septal defect. The tricuspid valve was larger than normal, the mitral valve showing complete atresia. The right lung showed three lobes, the left six. The liver was transposed as were stomach, pancreas and duodenum.

Case 5. Chinese male, aged 2 months. Complaint: fever. The child was dead on arrival at hospital. P.M. 439/55. There was a biloculate heart, exhibiting a corrected transposition of the great vessels. The liver was symmetrical, the gall bladder being in the left lobe. Stomach, pancreas and duodenum were transposed. There was an abnormally long central mesentery.

Case 6. Chinese female, aged 4 months. Complaint: cough, dyspnoea and cyanosis. P.M. 1332/56. There was a very large ventricular and several small atrio-septal defects. A common truncus arose, over-riding the septal defect and giving off a common pulmonary artery which later divided to supply each lung. Both lungs showed four imperfectly formed lobes and were the seat of a lobar type of pneumonia. There was complete transposition of all the abdominal viscera.

Case 7. Chinese male, aged 18 months. Complaint: cyanosis and fever. P.M. 1877/58. There was a cor triloculare biventriculare. The lungs showed a purulent bronchitis. Apart from absence of the spleen no other intra-abdominal abnormalities were detected.

The first case of splenic agenesis in a child with concomitant cardiac anomalies was recorded by Martin in 1826. At autopsy he found the stomach to be right-sided, the liver to be central, the aorta 
and pulmonary artery transposed, the left superior vena cava present, and a cor triloculare biatriatum, or, as he remarked, 'the heart of a fish'. By 1952 Polhemus and Schafer were able to collect from the literature 26 cases in infants and 10 in adults, including four infants of their own. They tabulated the defects most commonly found, and noted atrioventricularis communis in 11 of the infants. The adults showed no heart lesions and seemed quite unaffected by the absence of the spleen, one indeed living to her seventy-third year (Sternberg, 1903). Gilbert, Nishimura and Wedum (1958) feel that the spleen has probably been destroyed in those who show no cardiac defects and who die from prolonged chronic infection or neoplasia.

Ivemark (1955) collected 65 cases in children from the world literature and noted that splenic agenesis is usually associated with incomplete fusion of the A-V cushions. Of his cases 61 had some form of cono-truncus lesion, the most common being persistent truncus arteriosus, transposition of the great vessels, pulmonary atresia, cor biloculare and cor triloculare biatriatum. In 33 there was transposition of the stomach, and many showed anomalous lobulation of the lungs.

The most recent review is that of Gilbert et al. (1958), who tabulate the morbid findings in 104 adults and children.

The majority of the reported cases with concomitant heart disease have been in persons of white race, although the lesion has been observed in a Chinese (Hu, 1929), a Japanese (Kimura, 1930) and in five Negroes (Shapiro, 1930; Leikin, 1951; Gilbert et al., 1958).

Bush and Ainger (1955) describe with clarity the blood findings in their case. The peripheral blood showed anisocytosis and hypochromia of the red cells. Numerous target cells were present. At the age of 1 year there were 5,000 normoblasts per c.mm. They noted numerous Howell-Jolly bodies. There was a marked increase of resistance to haemolysis by hypotonic saline solutions. The plasma iron was low, the plasma copper high, features characteristic of iron deficiency in infancy (Lahey, Gubler, Cartwright and Wintrobe, 1953). Siderocytes were not present, although the administration of iron resulted in a brisk siderocyte and reticulocyte response; the Howell-Jolly bodies, normoblasts and target cells persisted. They were unable to demonstrate the Heinz bodies that Gasser and Willi $(1952,1955)$ felt were pathognomonic for the condition. Nihoyannopoulos, Zannos, Oeconomou-Mavrou and Statherou (1956) found normoblasts, target cells and Heinz bodies in the peripheral blood of a 2-month-old Greek girl, but no siderocytes or Howell-Jolly bodies were seen. Gilbert et al. (1958) found normoblasts in the peripheral blood of their five cases, but make no mention of Howell-Jolly or Heinz bodies. It appears that the blood picture is not as characteristic as Gasser and Willi (1952) have claimed; rather, it is very like that found after splenectomy. The haemoglobinopathies and haemolytic anaemias must be excluded before the diagnosis is made.

Instances of asplenia with a normal heart are relatively few, Gilbert et al. (1958) collecting 28 from the literature. A further case is recorded below.

Case 8. Chinese female, aged 4 years. Complaint: convulsions and fever. On lumbar puncture gram positive diplococci were demonstrated. P.M. 268/59. The heart was normal; the ductus arteriosus was closed. The lungs were congested. The peritoneal cavity contained about $200 \mathrm{ml}$. of faintly turbid fluid. The mesenteric glands were enlarged and congested. Apart from absence of the spleen there was no other intra-abdominal abnormality. The splenic vessels were present although slightly smaller than normal. The brain was thinly covered, particularly over the vertex, by a greenish-yellow pus from which pneumococci were grown. The middle ears were normal.

King and Shumacker (1952) have drawn attention to the relative frequency of infections generally, and of meningitis in particular, in those who have undergone splenectomy in infancy. Ivemark (1955) found five cases of meningitis in 66 cases of asplenia, including a 9-month-old female child without cardiovascular anomaly.

\section{Multilobulate Spleen}

Although agenesis is relatively rare, the association of mutilobulation of the spleen with congenital heart disease is even rarer. The writer has been able to trace only 17 such cases in the literature (Lochte, 1898; Geipel, 1903; Royer and Wilson, -1908; Miller, 1925; Putschar, 1934; Ivemark, 1955; Greenberg, 1957).

In the majority the cardiac abnormalities found were of a much more sophisticated nature than those seen in simple agenesis. Lochte (1898) describes transposition of the great vessels, pulmonary stenosis and transposed A-V valves in a left-sided heart. The tricuspid valve was irregular and malformed, and there were anomalous systemic and venous connections.

In the case of Royer and Wilson (1908) there were five transposed spleens, levocardia, transposition of the great vessels and malformed A-V valves.

Miller (1925) found that in addition to the presence of six small dextroposed spleens, the 
common iliac and hemiazygos veins passed posteriorly behind the aorta to empty into a very large normally placed azygos vein. The inferior vena cava was represented by a small trunk running from the liver to the right auricle. The left innominate vein did not join the right but passed down to join a much enlarged coronary sinus. The aorta and pulmonary artery were transposed. There was persistence of the common A-V canal. The lungs were atypically lobed and fissured.

Greenberg (1957) found that the four pulmonary veins, the venae cavae and the coronary sinus emptied into a large common atrium, which possessed two distinct auricular appendages. There was a single four-leaflet $A-V$ valve attached to the apex of a common ventricle. The liver was normal. The stomach, pancreas and spleen were transposed. The splenic tissue weighed $6 \mathrm{~g}$. and consisted of 16 lobules held together by delicate bands of connective tissue. In view of the rarity of the lesion the following case is recorded in some detail.

Case 9. C.K.J., an 8-month-old Hokkien Chinese boy was admitted to the General Hospital, Singapore, on September 3, 1958, with five days' history of cough and fever. The tonsils were enlarged and inflamed. There was a diffuse systolic murmur over most of the praecordium. The liver was palpable two and a half fingerbreadths below the right costal margin. Numerous crepitations were heard over both lung bases. A radiograph showed the apex of the heart to be tilted, and the

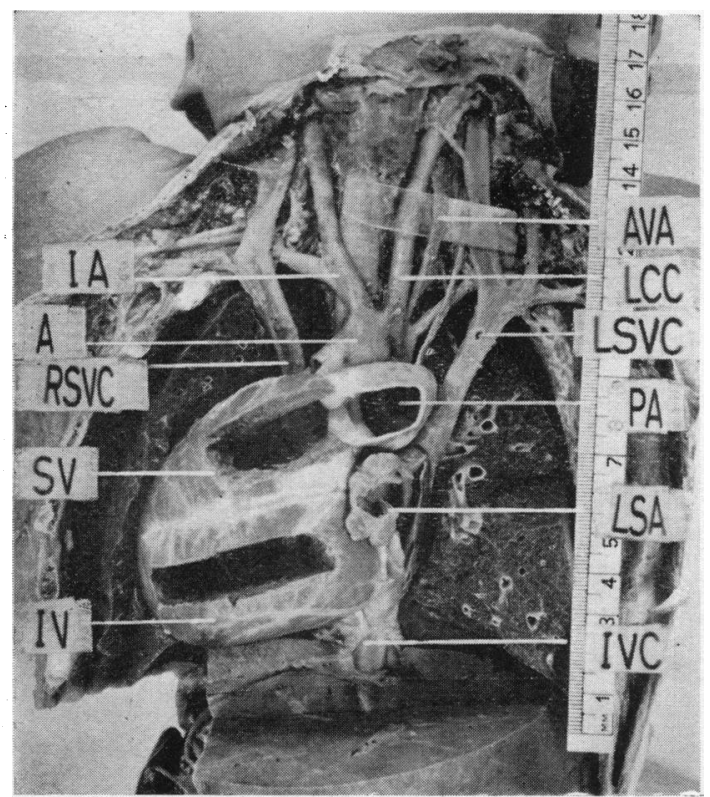

FIG. 1.-Shows the dissected thoracic organs. The symbols used are explained in the text.

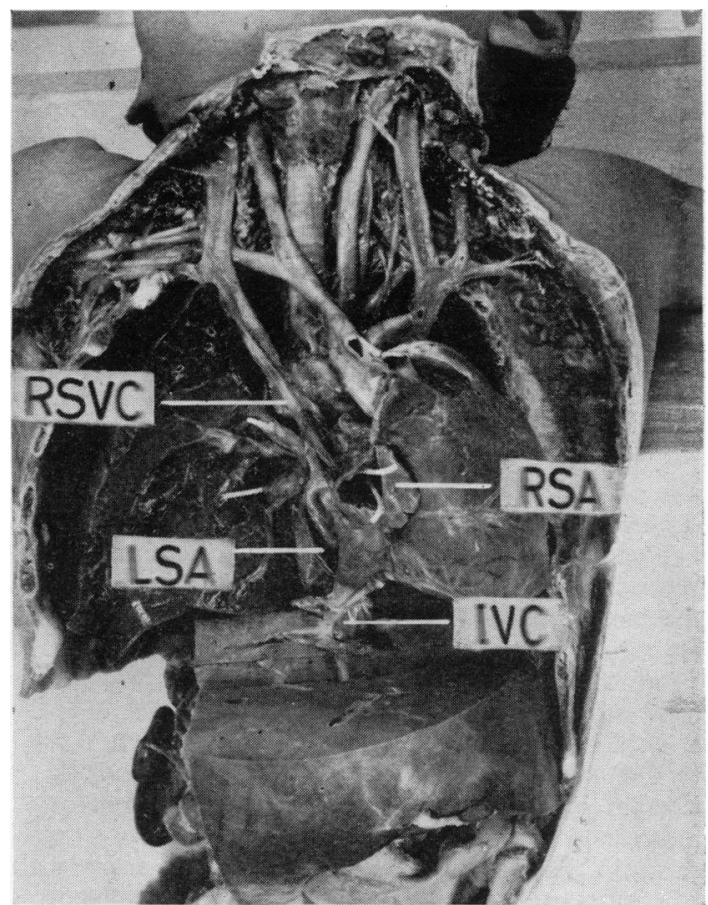

Fig. 2.-The heart has been displaced to the left. The plastic rods are in the two anomalous pulmonary veins which drain into the right-sided atrium. The junction of the right superior vena cava and the left-sided atrium is seen.

cardiac outline to be enlarged to both left and right of the sternum. The pulmonary vascular markings were prominent.

The child died three days after admission and an autopsy was performed (P.M. 1767/58). The right testicle was noted to be lower than the left. The heart was enlarged, lay transversely and was, for the most part, in the right side of the chest (Fig. 1).

There were twin superior venae cavae (RSVC and LSVC). That on the left drained into the apex of a leftsided atrium (LSA), receiving, just before doing so, a left-sided vena azygos. Both the myocardium and endocardium of this chamber were thickened. It was larger than usual, measuring $4.0 \mathrm{~cm}$. in the saggital plane and $2.0 \mathrm{~cm}$. in the coronal. At its mid-point posteriorly it received two pulmonary veins from the right lung, and at a comparable point nearer the left lateral border two left pulmonary veins. Lying more medially and above the pulmonary veins was a patent foramen ovale $0.8 \mathrm{~cm}$. in diameter, which was covered in part by a valvular septum. Passing behind the ventricles the RSVC entered the LSA posteriorly at a point midway between the entrance of the pulmonary veins and the junction of the inferior vena cava (IVC) with the LSA (Fig. 2). Anteriorly, between the point of junction of the RSVC and IVC, the coronary sinus drained into the LSA.

Blood flowed from the LSA through a normal tricuspid 
valve into a large inferiorly lying ventricle (IV). This chamber was dilated; the wall was $0.9 \mathrm{~cm}$. thick. Blood then passed almost vertically through a large ventricular septal defect $1.7 \mathrm{~cm}$. in diameter to gain a much smaller superiorly placed ventricle (SV) whose wall was $0.8 \mathrm{~cm}$. thick. At the apex of this chamber a muscular septum divided the pulmonary artery (PA) from the posteriorly placed aorta (A).

The right-sided atrium (RSA) was small, lay posteriorly and received two pulmonary veins from the right lung (Fig. 2). Blood left the RSA, which lay anterior to the RSVC, through a normal three-cusped valve to gain the $S V$.

The PA was dilated, being $2 \cdot 2 \mathrm{~cm}$. in diameter. The pulmonary valves were normal. There was a small patent ductus arteriosus. The aorta was of normal calibre and was left-sided. A large coronary artery arose behind the posteromedial aortic cusp to pass between the ventricles. A very small coronary artery arose behind the most anterior aortic cusp to pass between the RSA and SV. The aorta gave off four vessels from its arch. From right to left they were: (1) the innominate artery (IA) which divided normally; (2) the left common carotid artery (LCC); (3) an accessory vertebral artery (AVA), which passed posteriorly to lie behind the left internal carotid artery and which disappeared into a foramen of a transverse process at the level of the thyroid cartilage (C4); and, (4) the left subclavian artery which gave off a very small vertebral vessel which entered its vertebral foramen normally at the level of C6. The vertebral artery on the right side was normal.

The lungs were irregularly fissured and both showed two major lobes. The right lung, as noted previously, showed an anomalous distribution of the pulmonary veins and had a well marked cardiac impression.

The stomach, duodenum and pancreas were transposed. The splenic vessels ran normally beyond the tail of the pancreas, breaking up to supply an aggregation of nine splenunculi. These masses of splenic tissue were enveloped in a loose connective tissue network and taken together made up a normal sized spleen (Fig. 3). The individual splenunculi varied in diameter from 2.5 to $0.5 \mathrm{~cm}$. The caecum and appendix were central, being attached by a long central mesentery. The descending colon was on the right side.

It will be apparent from the case recorded above, and the brief descriptions of a few of the other specimens, that the cardiac lesions associated with multilobulate spleen may be very complex. It is worth remembering that portions of tissue which grossly resemble splenunculi may on histological examination prove to be accessory livers (Ivemark, 1955; Cases 9 and 11).

The association of cardiac malformation with splenic anomaly may be explained by the assumption that the teratogenic agent, which affects the developing heart, damages the developing spleen at one and the same time. The splenic primordium has been shown by Ivemark (1955) to appear when the embryo is in Horizons XV-XVII. At this time contact between the dorsal and ventral endocardial cushions has just been established, and separation of the truncus arteriosus into its aortic and pulmonary componer ts is under way, hence the predominance of cono-truncus lesions.

Broman (1921) has shown that late in the third embryonal month a series of notches ('Inscisuren') appear in the splenic primordium. Should the noxious agent strike at this time, an arrest of fusion may occur, the partitioned spleen continuing to grow, making up on aggregate the normal bulk of splenic tissue. Damage to the heart at this time would result in the more complex type of lesion seen with multilobulate spleen. It is probable that multilobulation may occur at an earlier date as Ivemark (1955) found notches in the splenic primordium of an embryo in Horizon XVI, which would correspond to an ovulation age of 32-34 days (Streeter, 1948).

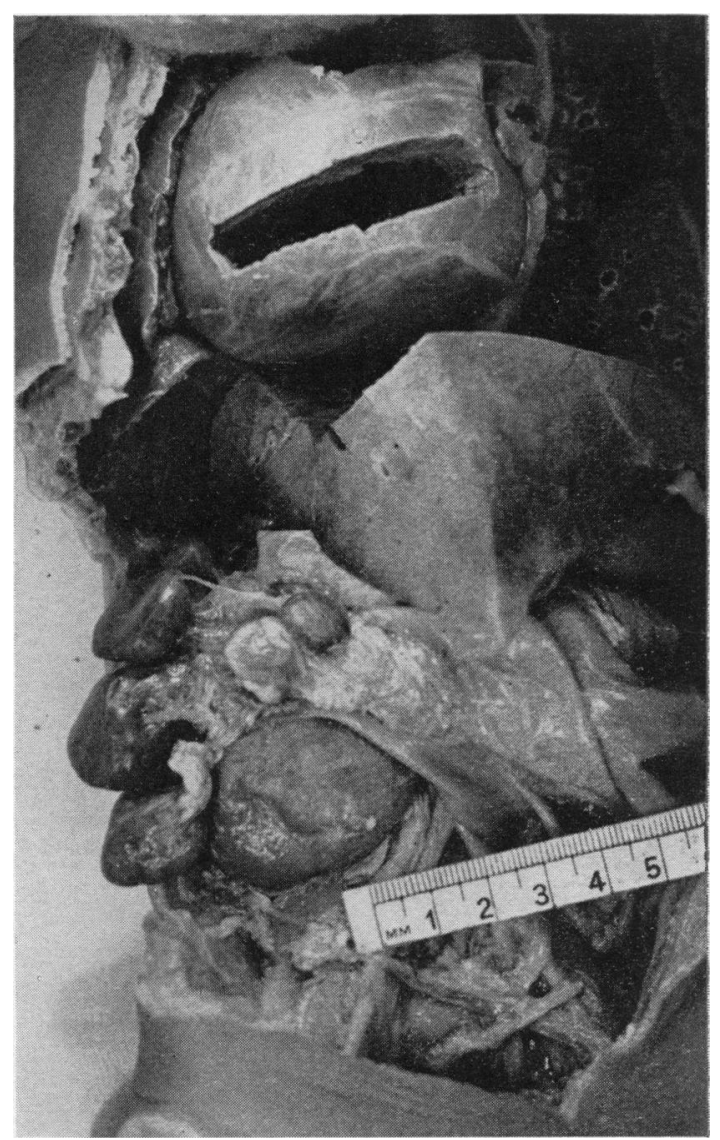

Fig. 3.-The multilobulate spleen is seen in the lateral view. 
It may be asked why splenic agenesis should be so rare when congenital heart disease is so common. Gasser and Willi (1952) consider it quite certain that the causative factor is endogenous, a lethal factor with pleiotropic effects. This hypothesis, although difficult to prove, would explain the discrepancy. It may be that the noxious agent which damages the heart destroys a large part of the splenic tissue present. Should none survive, then 'agenesis' would be the end result. However, should a small amount of splenic material survive the initial assault, a rapid increase in the remainder would make good the damage done, as the spleen is known to have excellent regenerative powers.

\section{Summary}

Seven cases of splenic agenesis associated with cono-truncus heart lesions, occurring in Chinese children in Singapore, are briefly described.

A single case of asplenia, without cardiac malformation, dying from pneumococcal meningitis, and a case of multilobulate spleen with gross cardiac anomalies are reported.

The embryological significance of the association of congenital heart disease with asplenia. and with multilobulate spleen, is discussed.

I wish to thank Professor R. Kirk for many useful suggestions, Dr. T. Balasingham and Dr. E. B. La'Brooy for access to their autopsy notes and material, Dr. C. Elaine Field of the Paediatric Unit, General Hospital, Singapore, for permission to quote briefly from case records, Mr. V. Nalpon for the photographs, and Mr. P. A. Samuel who typed the script.

\section{REFERENCES}

Broman, I. (1921). Quoted by Ivemark (1955) loc. cit.

Bush, J. A. and Ainger, L. E. (1955). Pediatrics, 15, 93.

Gasser, C. and Willi, H. (1952). Helv. paediat. Acta, 7, 369.

Geipel, P. (1903). Arch. Kinderheilk., 35, 112.

Gilbert, E. F., Nishimura, K. and Wedum, B. G. (1958). Circulation, 17, 72 .

Greenberg, S. D. (1957). A.M.A. Arch. Path., 63, 333.

Hu, C. H. (1929). Amer. J. Path., 5, 389.

Ivemark, B. I. (1955). Acta paediat. (Uppsala), 44, suppl. 104.

Kimura, H. (1930). Jap. med. World, 10,63.

Kimura, H. (1930). Jap. med. World, 10, 63. Surg., 136, 239.

King, H. and Shumacker, H. B. (1952). Ann. Surg., 136, 239. (1953). J. clin. Invest., 32, 329.

Leikin, S. L. (1951). Clin. Proc. Child. Hosp. Wash., 7, 236. Quoted by Bush and Ainger (1955)

Lochte (1898). Beitr. path. Anat., 24, 187.

Martin, G. (1826). Bull. Soc. anat. Paris, 1, 39.

Miller, A. J. (1925). Amer. J. Path., 1, 467.

Muir, C. S. (1959). Archives of Disease in Childhood, 34, 231.

Nihoyannopoulos, J., Zannos, L., Oeconomou-Mavrou, C. and yannopoulos, J., Zannos, L., Oeconomou-
Statherou, E. (1956). J. clin. Path., 9, 323.

Polhemus, D. W. and Schafer, W. B. (1952). Pediatrics, 9, 696. Putschar, W. (1934). Quoted by Ivemark (1955).

Royer, B. F. and Wilson, J. D. (1908). Arch. Pediat., 25, 881.

Shapiro, P. F. (1930). Arch. Path. (Chicago), 9, 54.

Sternberg, C. (1903). Virchows Arch. path. Anat., 173, 571.

Sternberg, C. (1903). Virchows Arch. path. Anat., 173, 571.

Willi, H. and Gasser, C. (1955). Et. néonatal., 4, 25. 